\title{
Spectral identification and quantification of salts in the Atacama Desert
}

\author{
Harris, J. K. ${ }^{1,2}$, Cousins, C. R. ${ }^{3}$, Claire, M. W. ${ }^{3}$. \\ 1. Department of Earth and Planetary Sciences, Birkbeck University of London, London, UK. \\ 2. UCL/Birkbeck Centre for Planetary Sciences, University College London, London, UK. \\ 3. Department of Earth and Environmental Sciences, University of St Andrews, St Andrews, UK.
}

\begin{abstract}
Salt minerals are an important natural resource. The ability to quickly and remotely identify and quantify salt deposits and salt contaminated soils and sands is therefore a priority goal for the various industries and agencies that utilise salts. The advent of global hyperspectral imagery from instruments such as Hyperion on NASA's Earth-Observing 1 satellite has opened up a new source of data that can potentially be used for just this task. This study aims to assess the ability of Visible and Near Infrared (VNIR) spectroscopy to identify and quantify salt minerals through the use of spectral mixture analysis. The surface and near-surface soils of the Atacama Desert in Chile contain a variety of well-studied salts, which together with low cloud coverage, and high aridity, makes this region an ideal testbed for this technique. Two forms of spectral data ranging $0.35-2.5 \mu \mathrm{m}$ were collected: laboratory spectra acquired using an ASD FieldSpec Pro instrument on samples from four locations in the Atacama desert known to have surface concentrations of sulfates, nitrates, chlorides and perchlorates; and images from the EO-1 satellite's Hyperion instrument taken over the same four locations. Mineral identifications and abundances were confirmed using quantitative XRD of the physical samples. Spectral endmembers were extracted from within the laboratory and Hyperion spectral datasets and together with additional spectral library endmembers fed into a linear mixture model. The resulting identification and abundances from both dataset types were verified against the sample XRD values. Issues of spectral scale, SNR and how different mineral spectra interact are considered, and the utility of VNIR spectroscopy and Hyperion in particular for mapping specific salt concentrations in desert environments is established. Overall, SMA was successful at estimating abundances of sulfate minerals, particularly calcium sulfate, from both hyperspectral image and laboratory sample spectra, while abundance estimation of other salt phase spectral end-members was achieved with a higher degree of error.
\end{abstract}

Keywords: Spectra Mixture Analysis, salts, Hyperion, hyperspectral, Atacama Desert

\section{Introduction}

There are numerous types of salt minerals found in sediments across the globe (and solar system), and their presence can have significant impacts on nearby life, both positively and negatively. Identifying these salts and quantifying their abundance is therefore an important consideration. Reflectance spectroscopy can be used to characterise minerals, with different salt minerals having key diagnostic spectral features in the visible and near infrared portion of the spectrum ${ }^{1-4}$. Knowledge of these spectral properties can be exploited through the use of imaging spectrometers to map the occurrence of different saline-affected soils and surfaces ${ }^{5}$. The spectral properties that are most useful are spectral absorptions, and with the advent of hyperspectral imagers with spectral resolutions of as little as $10 \mathrm{~nm}$ these narrow band absorptions can potentially be captured in high spatial resolution data. Airborne hyperspectral imagers AVIRIS and HyMap have both been used to successfully identify and map saline minerals in Death Valley, California ${ }^{6}$ and the Murray-Darling Basin in southeast Australia ${ }^{7}$ respectively. Satellite hyperspectral imaging is a concept that has been successfully utilised in the exploration of other bodies in the Solar System ${ }^{8}$, and two experimental instruments have been flown on Earth Observation platforms, CHRIS on ESA's Proba- $1^{9}$ and Hyperion on NASA's Earth Observer $1^{10}$. The easy availability of these high spectral- and spatial-resolution datasets has encouraged the need for new analysis techniques that can take advantage of this extra information. Spectral mixture analysis (SMA) or "spectral unmixing" is one such family of techniques that allows both qualitative and quantitative information to be extracted from hyperspectral images. SMA techniques have been previously applied to Hyperion imagery to evaluate a number of different mineral and environment types. Mining interests have been investigated with Magendran and Sanjeevi ${ }^{11}$ classifying iron ore and Hosseinjani Zadeh et al ${ }^{12}$ mapping a porphyry copper belt. Ghosh et $\mathrm{al}^{13}$ utilised Hyperion imagery to characterise and map salinated soil in the Indo-Gangetic

Earth Resources and Environmental Remote Sensing/GIS Applications VII, edited by Ulrich Michel, Karsten Schulz, Manfred Ehlers, Konstantinos G. Nikolakopoulos, Daniel Civco, Proc. of SPIE Vol. 10005, 100050I (C) 2016 SPIE · CCC code: $0277-786 X / 16 / \$ 18 \cdot$ doi: $10.1117 / 12.2241520$ 
plains in India. Minimum Noise Fraction (MNF) transformations and Pixel Purity Index (PPI) analysis techniques were combined with linear spectral unmixing to quantify the severity of the salination in the regions examined. This study however did not look to identify specific salt mineral species or to estimate their absolute abundance.

The Atacama desert is located along the western Pacific coast of South America and contains the driest non-polar regions on Earth, receiving less than $100 \mathrm{~mm}$ of rain each year ${ }^{14}$. Subregions within the Atacama are described as "the driest regions on Earth" with precipitation averaging below $1 \mathrm{~mm}$ per year ${ }^{15,16}$ and these unique locales are the focus of this investigation. The desert soils are formed from largely granitic lithologies ${ }^{17}$ and their hyper-aridity has allowed concentrations of atmospherically-derived nitrates, sulfates, chlorides and perchlorates to accumulate in the upper surface layers ${ }^{18}$. The region has long been host to nitrate mines ${ }^{19}$ at the surface and near-surface making it a geologically wellcharacterised region ${ }^{18}$. The lack of surface water makes these soils ideal for testing the use of hyperspectral data to identify and quantify salt minerals as water absorption bands can obscure many of the diagnostic features of these minerals. Work by Sutter et $\mathrm{a}^{20}$ using laboratory based VNIR spectral analysis of Atacama surface and near-surface samples confirmed the presence quartz, albite, microcline, smectite, kaolinite, chlorite, gypsum, anhydrite and calcite. Their study examined the mineral abundance in each sample using XRD achieving a $10-20 \%$ absolute abundance accuracy but no attempt was made to calculate abundance from the VNIR data. More recent work by Flahaut et $\mathrm{al}^{21}$ has used field spectroscopy and Hyperion data to characterise the mineralogy of the Atacama salar deposits. These surface deposits form where groundwater upwells into otherwise hyperarid regions, and are dominated by halite, clays and sulfates including gypsum. Discrimination between salt dominated and clay dominated soils was demonstrated using the field VNIR spectra but further quantitative discussion was not presented.

In this study we aim to build on these previous studies by investigating the spectral properties of the Atacama Desert and its uniquely arid and salt-rich soils. The ability to identify and quantify salt minerals through the application of SMA techniques to VNIR spectral data and in particular hyperspectral images from the Hyperion satellite shall be established. 


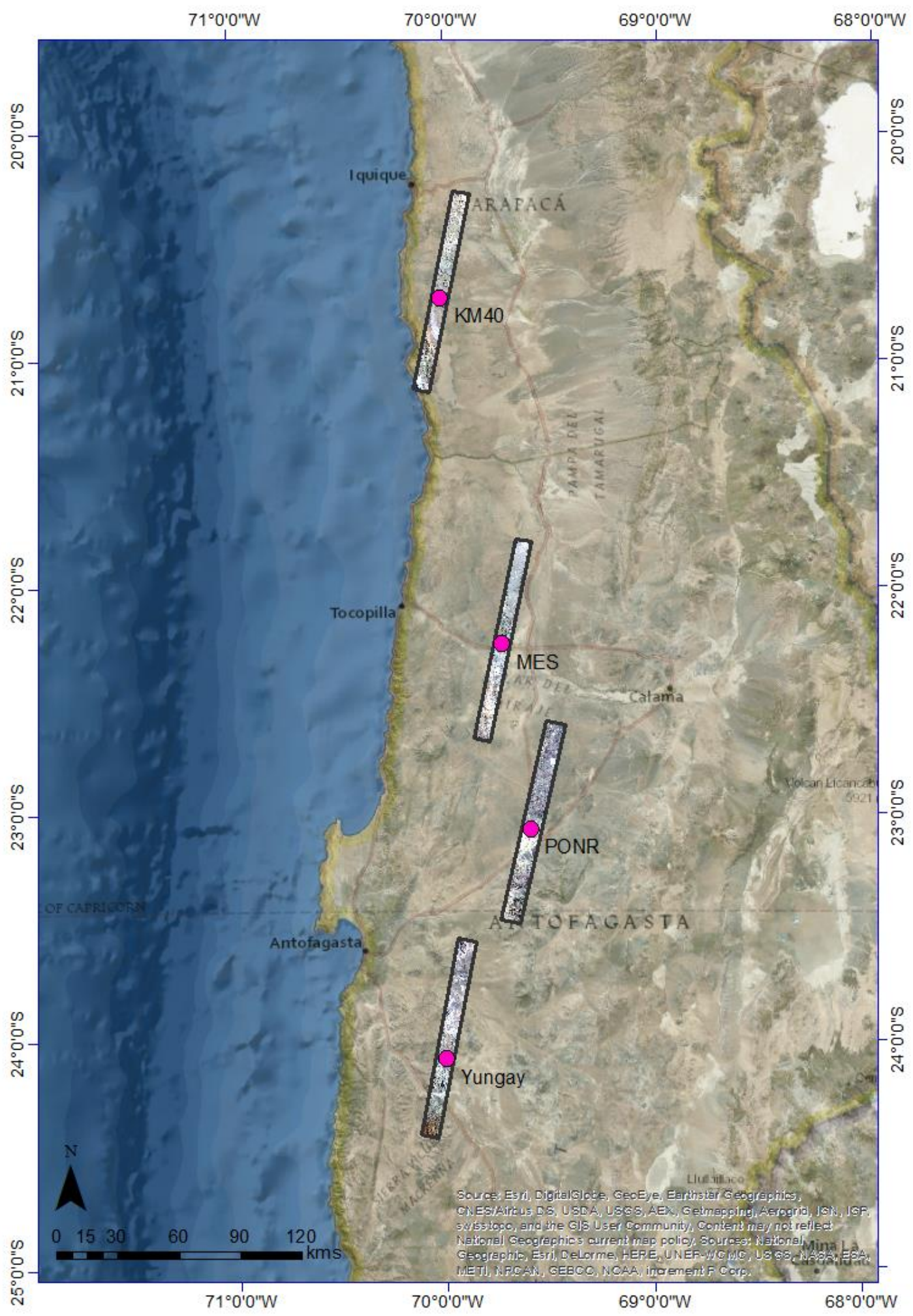

Figure 1: The Atacama Desert with the four sample locations marked in pink circles with the footprint of the relevant Hyperion images overlain. 


\section{Data sources and processing}

\subsection{Soil samples}

32 individual sediment samples (Table 1) were collected from the surface and up to a depth of $1 \mathrm{~m}$ at four locations (Figure 1) across the hyper-arid section of the Atacama Desert ${ }^{14}$ in 2010 and 2012. Wet chemistry IC analysis was performed and the presence of sulfate, nitrate, chloride and perchlorate anions confirmed in all 32 samples. VNIR reflectance spectra were collected from all 32 and quantitative XRD performed on 15 of the samples (Table 1) providing the identities and relative abundances of the minerals present in each.

Table 1: Atacama samples and the analysis that was performed for each

\begin{tabular}{|c|c|c|c|c|}
\hline Site & Sample & Wet Chemistry IC & VNIR spectroscopy & Quantitative XRD \\
\hline \multirow{7}{*}{ Yungay } & Y2_AT12 & $\mathrm{X}$ & $\mathrm{X}$ & $\mathrm{X}$ \\
\hline & AT12-T1-2 & $\mathrm{X}$ & $\mathrm{X}$ & \\
\hline & AT12-T1-14 & $\mathrm{X}$ & $\mathrm{X}$ & \\
\hline & AT12-T1-18 & $\mathrm{X}$ & $\mathrm{X}$ & \\
\hline & AT12-T1-17 & $\mathrm{X}$ & $\mathrm{X}$ & \\
\hline & AT12-T1-19 & $\mathrm{X}$ & $\mathrm{X}$ & $\mathrm{X}$ \\
\hline & AT12-T1-21 & $\mathrm{X}$ & $\mathrm{X}$ & $\mathrm{X}$ \\
\hline \multirow[t]{6}{*}{ PONR } & PONR $0 \mathrm{~cm}$ & $\mathrm{X}$ & $\mathrm{X}$ & $\mathrm{X}$ \\
\hline & PONR $40 \mathrm{~cm}$ & $\mathrm{X}$ & $\mathrm{X}$ & $\mathrm{X}$ \\
\hline & PONR $80 \mathrm{~cm}$ & $\mathrm{X}$ & $\mathrm{X}$ & \\
\hline & PONR $90 \mathrm{~cm}$ & $\mathrm{X}$ & $\mathrm{X}$ & \\
\hline & PONR $100 \mathrm{~cm}$ & $\mathrm{X}$ & $\mathrm{X}$ & $\mathrm{X}$ \\
\hline & PONR crusts & $\mathrm{X}$ & $\mathrm{X}$ & \\
\hline \multirow{2}{*}{ MES } & MES $0 \mathrm{~cm}$ & $\mathrm{X}$ & $\mathrm{X}$ & $\mathrm{X}$ \\
\hline & MES $20 \mathrm{~cm}$ & $\mathrm{X}$ & $\mathrm{X}$ & $\mathrm{X}$ \\
\hline \multirow[t]{17}{*}{ KM40 } & KM40_PT23 & $\mathrm{X}$ & $\mathrm{X}$ & \\
\hline & KM40-PT24 & $\mathrm{X}$ & $\mathrm{X}$ & \\
\hline & KM40-PT25 & $\mathrm{X}$ & $\mathrm{X}$ & \\
\hline & KM40-PT27 & $\mathrm{X}$ & $\mathrm{X}$ & $\mathrm{X}$ \\
\hline & KM40-PT28 & $\mathrm{X}$ & $\mathrm{X}$ & $\mathrm{X}$ \\
\hline & KM40-PT29 & $\mathrm{X}$ & $\mathrm{X}$ & \\
\hline & AT12_T3_4 & $\mathrm{X}$ & $\mathrm{X}$ & \\
\hline & AT12_T3_5 & $\mathrm{X}$ & $\mathrm{X}$ & $\mathrm{X}$ \\
\hline & AT12_T3_8 & $\mathrm{X}$ & $\mathrm{X}$ & \\
\hline & AT12_T3_12 & $\mathrm{X}$ & $\mathrm{X}$ & $\mathrm{X}$ \\
\hline & AT12_T3_13 & $\mathrm{X}$ & $\mathrm{X}$ & \\
\hline & AT12_T3_15 & $\mathrm{X}$ & $\mathrm{X}$ & \\
\hline & AT12_T3_17 & $\mathrm{X}$ & $\mathrm{X}$ & $\mathrm{X}$ \\
\hline & AT12_T3_19 & $\mathrm{X}$ & $\mathrm{X}$ & \\
\hline & KM40A & $\mathrm{X}$ & $\mathrm{X}$ & \\
\hline & KM40B & $\mathrm{X}$ & $\mathrm{X}$ & $\mathrm{X}$ \\
\hline & KM40C & $X$ & $X$ & $X$ \\
\hline
\end{tabular}

\subsubsection{Ion Chromatography}

After discarding a $>1.4 \mathrm{~mm}$ fraction, samples were crushed, extracted at 10:1 water:soil ratio for 30 minutes on heated $\left(30^{\circ} \mathrm{C}\right)$ shake-table, centrifuged, and passed through a 0.2 um cellulose acetate filter. Perchlorate analyses were performed on Metrohm $930 \mathrm{IC}$, with a $150 \mathrm{~mm}$ Metrosep Asupp5 separation column (4 mm bore) using $10 \mathrm{mM} \mathrm{Na} \mathrm{CO}_{3}$ eluent at a flow rate of $0.7 \mathrm{ml} / \mathrm{min}$. After quantifying perchlorate, samples were further diluted so as to bring perchlorate 
concentrations below $1 \mathrm{ppb}$, and nitrate, sulfate, chloride were analysed using the same column but with a $3.1 \mathrm{mM}$ $\mathrm{Na}_{2} \mathrm{CO}_{3} / 1 \mathrm{mM} \mathrm{NaHCO}$ eluent at a flow rate of $0.7 \mathrm{ml} / \mathrm{min}$. This two-step process was required because in the latter method perchlorate is retained on the column longer than the typical integration time of the typical (EPA 300.1) "7 anion" method, and can thus cause spurious results if above detection limits. Details of the methodology and anion weight percentages will be presented elsewhere - In this study, we simply used the chromatograms to confirm the presence of the anions.

\subsubsection{Laboratory VNIR reflectance spectroscopy}

Sub-samples of all 32 samples were selected for Visible and Near Infrared (VNIR) analysis. These were left in their unconsolidated and unprocessed state to best represent the original desert surface. Spectra were collected using an ASD Fieldspec Pro at the NERC Field Spectroscopy Facility at the University of Edinburgh. The Fieldspec Pro was used with the fibre-optic contact probe attachment and spectra collected in the range $0.35-2.5 \mu \mathrm{m}$ with spectral FWHM of $3-12$ $\mathrm{nm}$. Prior to each measurement the optimisation routine was run and both a dark current and calibrated Spectralon@ white reference spectra were taken. For each sample, six individual spectra were taken with the sample holder being repositioned with respect to the instrument contact probe between each measurement. These six spectra were then averaged to account for any bias introduced by the random nature of the particle size and positioning within the sample. Little distinguishing spectral variation was evident in the visible portion of the spectra and the final dataset was trimmed to cover $1.0-2.5 \mu \mathrm{m}$. All subsequent SMA was performed using this NIR set.

The final laboratory spectra covered a peak reflectance range of $0.32-0.86$. All spectra contained common absorptions at approximately 1.4 and $1.9 \mu \mathrm{m}$ indicating the presence of $\mathrm{O}-\mathrm{H}$ and $\mathrm{H}_{2} \mathrm{O}$ bonds within minerals in every sample (Figure 2). An absorption at approximately $2.22 \mu \mathrm{m}$ is also observed in every sample, indicating the presence of either metal-O-H bonds or combination $\mathrm{H}_{2} \mathrm{O}$ and $\mathrm{S}-\mathrm{O}$ bonds ${ }^{22}$. Shallow $\mathrm{Fe}^{3+}$ electron transition absorptions in the $0.9-1.0 \mu \mathrm{m}$ range are also present in all samples indicating the presence of small amounts of iron-oxides, iron hydroxides or iron bearing silicates.

\subsubsection{X-Ray Diffraction}

15 of the 32 samples were selected for Quantitative XRD (Q-XRD) mineralogical analysis at the University of St Andrews (Table 1). Samples were selected to span the range of visual and spectral variation observed across the whole sample set (Figure 2). Samples were crushed to $<5 \mu \mathrm{m}$ using an agate ball mill in acetone followed by drying overnight and backpacked into standard mounts to produce maximum random orientation. These were analysed with a Philips PW1050 / Hiltonbrooks DG2, followed by Rietveld quantification using SiroQuant v.3. Thirteen different minerals were identified across all samples analysed, including three different calcium sulfates (anhydrite, bassanite and gypsum), and one chloride, halite (Table 2). Perchlorates and nitrates were confirmed in the IC analysis but no perchlorate or nitrate bearing minerals were identified in the Q-XRD analysis suggesting that these salts are present only in trace quantities. Due to the significant percentage of plagioclase in the samples, the errors on the abundances calculated is taken to be $10 \%$ absolute abundance. 
Table 2: Q-XRD mineral identification and abundance values (Anh - anhydrite, Bas - bassanite, Cal - calcite, Chl - chloride, Gyp - gypsum, Hal - halite, Hem - hematite, Hor - hornblende, K-F - K-Feldspar, Mic - mica, Pla - plagioclase, Pyr - pyroxene, Qua - quartz)

\begin{tabular}{|l|c|c|c|c|c|c|c|c|c|c|c|c|c|}
\hline & Anh & Bas & Cal & Chl & Gyp & Hal & Hem & Hor & K-F & Mic & Pla & Pyr & Qua \\
\hline Y2-AT12 & $5 \%$ & & & $4 \%$ & $19 \%$ & & & $2 \%$ & $6 \%$ & $3 \%$ & $40 \%$ & & $23 \%$ \\
\hline AT12-T1-19 & $\operatorname{tr}$ & & & $2 \%$ & $\operatorname{tr}$ & & & $4 \%$ & $12 \%$ & $2 \%$ & $60 \%$ & & $21 \%$ \\
\hline AT12-T1-21 & $8 \%$ & & & $3 \%$ & $8 \%$ & & & $4 \%$ & $7 \%$ & $\operatorname{tr}$ & $51 \%$ & & $20 \%$ \\
\hline PONR 0 cm & $1 \%$ & $9 \%$ & $2 \%$ & $1 \%$ & $1 \%$ & $1 \%$ & $2 \%$ & & $7 \%$ & $5 \%$ & $61 \%$ & $2 \%$ & $10 \%$ \\
\hline PONR 40 cm & $44 \%$ & & & & $23 \%$ & & & & $2 \%$ & & $27 \%$ & & $5 \%$ \\
\hline PONR 100 cm & $14 \%$ & $1 \%$ & $2 \%$ & $1 \%$ & $1 \%$ & $9 \%$ & $2 \%$ & & $4 \%$ & & $51 \%$ & $4 \%$ & $9 \%$ \\
\hline MES 0 cm & $1 \%$ & & & $1 \%$ & $5 \%$ & & & $5 \%$ & $4 \%$ & $7 \%$ & $55 \%$ & & $23 \%$ \\
\hline MES 20 cm & $1 \%$ & & & $2 \%$ & $7 \%$ & & & $5 \%$ & $4 \%$ & $6 \%$ & $53 \%$ & & $23 \%$ \\
\hline KM40-PT27 & $1 \%$ & & $2 \%$ & $2 \%$ & $7 \%$ & & $2 \%$ & $5 \%$ & $6 \%$ & & $52 \%$ & $7 \%$ & $15 \%$ \\
\hline KM40-PT28 & $3 \%$ & & & $1 \%$ & $18 \%$ & & $1 \%$ & $2 \%$ & $5 \%$ & & $49 \%$ & $5 \%$ & $16 \%$ \\
\hline AT-12-T3-5 & $32 \%$ & & & $1 \%$ & $18 \%$ & $6 \%$ & & $1 \%$ & $2 \%$ & & $33 \%$ & & $9 \%$ \\
\hline AT12-T3-12 & $12 \%$ & & & $2 \%$ & $15 \%$ & $3 \%$ & & $2 \%$ & $7 \%$ & $\operatorname{tr}$ & $38 \%$ & $5 \%$ & $16 \%$ \\
\hline AT12-T3-17 & $4 \%$ & & & $1 \%$ & $28 \%$ & & & $1 \%$ & $3 \%$ & & $47 \%$ & $2 \%$ & $14 \%$ \\
\hline KM40B & $15 \%$ & & & $2 \%$ & $9 \%$ & $5 \%$ & & $1 \%$ & $4 \%$ & & $49 \%$ & $2 \%$ & $13 \%$ \\
\hline KM40C & $29 \%$ & & & $2 \%$ & $6 \%$ & $5 \%$ & & $1 \%$ & $3 \%$ & & $41 \%$ & $14 \%$ \\
\hline
\end{tabular}




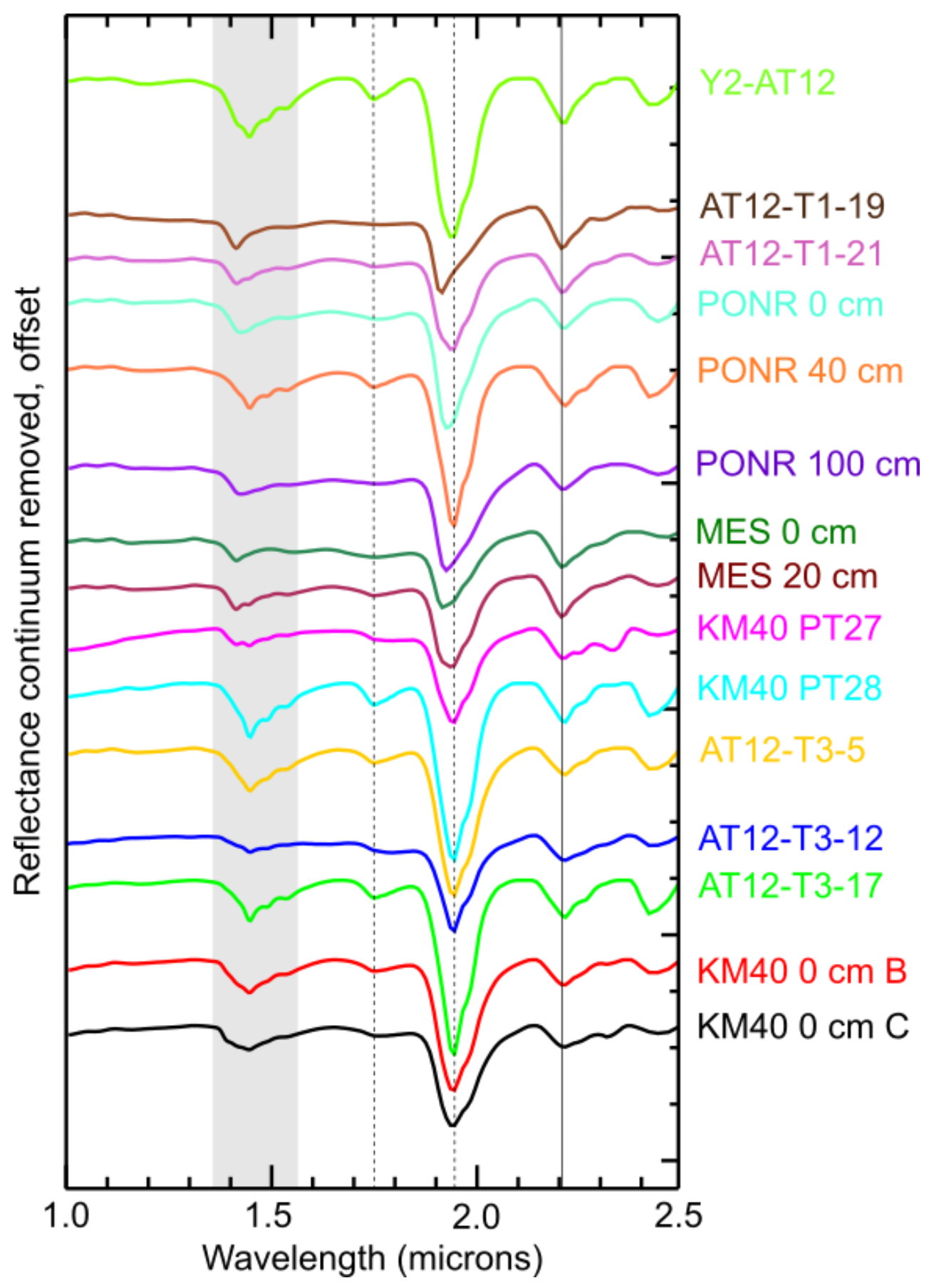

Figure 2: NIR laboratory spectra of samples selected for Q-XRD analysis. All samples show evidence of $\mathrm{H}_{2} \mathrm{O} / \mathrm{O}-\mathrm{H}$ bonds with absorptions around $1.4 \mu \mathrm{m}$ (grey shaded region) and $1.9 \mu \mathrm{m}$ (the second dotted line). Where this second hydration absorption is shifted from $1.91 \mu \mathrm{m}$ to $1.95 \mu \mathrm{m}$ this together with a smaller absorption at $1.75 \mu \mathrm{m}$ (the first dotted line) indicates the presence of gypsum. The solid line around $2.2 \mu \mathrm{m}$ indicates a metal-O- $\mathrm{H}$ bond or a combination of $\mathrm{S}-\mathrm{O}$ and $\mathrm{H}_{2} \mathrm{O}$ bonds within a single mineral (e.g. as found in gypsum). 


\subsection{Hyperion imagery}

The Hyperion Imaging spectrometer is an experimental Visible and Near Infrared (VNIR) hyperspectral reflectance spectrometer on board NASA's Earth-Observing 1 satellite. This pushbroom instrument is made up of two spectrometers that together span the wavelength range $0.4-2.5 \mu$ m over 242 spectral bands of approximately $11 \mathrm{~nm}$ FWHM ${ }^{23}$. Hyperion has a Signal to Noise Ratio (SNR) of approximately 160 at $0.55 \mu \mathrm{m}$ to 40 at $2.125 \mu \mathrm{m}^{23}$ and produces images with a pixel size footprint of roughly $29 \mathrm{~m}$ on the ground. Hyperion images were requested and taken in September 2015 and again in March 2016 (Table 3). Images were processed from L1R level using a mixture of Exelis ENVI 5.0 and Matlab routines. Images were destriped using the algorithm first described by Datt et $\mathrm{al}^{24}$ using a Matlab program contained within the hyperspectralToolbox v0.07. Using ENVI, bad bands and pixels were manually identified and removed, across track illumination correction was applied to partially remove spectral smile, and MODTRAN based atmospheric correction was conducted using the ENVI FLAASH plugin. Due to the lack of variation within the visible portion of the spectra each image was trimmed to remove bands below $1.0 \mu \mathrm{m}$. Due to high noise levels all bands above $2.355 \mu \mathrm{m}$ were also removed. Spectral smile is an issue that affects all hyperspectral imaging spectrometers and for Hyperion results in a wavelength shift of as much as $4 \mathrm{~nm}$ in the visible range and $1 \mathrm{~nm}$ in the shortwave infrared (SWIR) $)^{25}$. In this work only the SWIR portion of the image cubes are used and thus spectral smile is not considered a major issue. To minimise remaining noise a minimum noise fraction (MNF) transformation was performed on each image cube. The resulting MNF bands represented noise above band 10 to 20 depending on the image. Only bands below this were inverse transformed back into reflectance space to produce the final image cubes that were used in the spectral mixture analysis.

Table 3: Hyperion images requested and analysed for this study

\begin{tabular}{|l|l|l|l|l|l|l|}
\hline Site & $\begin{array}{l}\text { Sample } \\
\text { Lat. }\end{array}$ & $\begin{array}{l}\text { Sample } \\
\text { Lon. }\end{array}$ & Hyperion Image & Date & $\begin{array}{l}\text { Central } \\
\text { Lat. }\end{array}$ & $\begin{array}{l}\text { Central } \\
\text { Lon. }\end{array}$ \\
\hline Yungay & -24.0919 & -69.9975 & EO1H0010772015248110PF_AK3_01 & $05 / 09 / 15$ & -24.6181 & -70.0890 \\
\hline & & & EO1H0010772016068110KF_SG1_01 & $08 / 03 / 16$ & -24.5025 & -70.0431 \\
\hline & & & EO1H0010772016081110KF_SG1_01 & $21 / 03 / 16$ & -24.4444 & -70.0451 \\
\hline KM40 & -20.7332 & -70.0079 & EO1H0020742015251110PF_SG1_01 & $08 / 09 / 15$ & -21.1713 & -70.0685 \\
\hline & & & EO1H0020742016065110KF_SG1_01 & $05 / 03 / 16$ & -21.1697 & -70.0732 \\
\hline MES & -22.2608 & -69.7247 & EO1H0010752015240110PF_SG1_01 & $28 / 08 / 15$ & -22.7226 & -69.7953 \\
\hline PONR & -23.0772 & -69.5921 & EO1H0010762015245110KF_SG1_01 & $02 / 09 / 15$ & -23.5304 & -69.6662 \\
\hline & & & EO1H0010762016073110KF_AK3_01 & $13 / 03 / 16$ & -23.4743 & -69.6500 \\
\hline
\end{tabular}

\section{Analysis}

Reflectance spectra collected via imaging spectrometers are rarely the result of only one material and are more commonly a mixture of spectral signatures from various different materials (referred to as endmembers) within the area covered by each pixel. Linear spectral unmixing is a well understood analysis technique that models a pixel $(y)$ as a linear mixture of spectral signatures $(x)$ from a number of different endmembers $(p)$ that all lie within the spatial resolution of that pixel, plus some noise $(c)$. Each endmember contributes a percentage $(a)$ of the final pixel value.

$$
y=\sum_{i=1}^{p} a_{i} x_{i}+c
$$

A vast wealth of algorithms exist within the spectral unmixing literature ${ }^{26-29}$ covering the three potential unknowns within the problem. These are i) the number of endmembers present, ii) the endmember spectral signatures and iii) the endmember abundances in each pixel. The majority of these algorithms focus on the extraction of the endmember signatures and the estimation of the abundances, with the number of endmembers being known or decided upon a priori. In this study the SISAL algorithm of Bioucas-Dias ${ }^{30}$ is utilised to extract endmember spectra from within the datasets and the fully constrained linear least squared (FCLLS) algorithm described by Heinz and Chang ${ }^{31}$ used to estimate the volume 
abundance. Both algorithms are freely available as Matlab routines ${ }^{*}$ that are quick to run, requiring only a standard desktop computer and producing results in seconds allowing large volumes of data to be analysed quickly.

\section{Results}

\subsection{Laboratory sample spectra}

The SISAL algorithm was run on the 32 sample spectra dataset across a range of $p$ values from $p=5$ to 11 . For each $p$ value under consideration the algorithm was run $p$ times and the resulting endmembers matched across each set using the Spectral Angle Mapper ${ }^{32}$ (SAM) parameter. These matching spectra were averaged to produce a final endmember set with $p$ endmembers. $p=8$ was found to have the lowest SAM values between runs and the most realistic looking final spectra. The endmembers extracted using SISAL were examined and where possible identified as a specific mineral. Many of the minerals revealed by the XRD analysis have spectrally neutral high albedo reflectance spectra and endmember extraction algorithms can struggle to identify these ${ }^{33}$. Of the eight, two were identified as potential phyllosilicates, and one spectrally neutral endmember tentatively identified as halite. Halite is spectrally neutral in this wavelength range with the only features being a slightly positive slope and very shallow hydration features at 1.4 and $1.9 \mu \mathrm{m}^{34}$. Two endmembers were also a spectral match to gypsum. Gypsum and bassanite have similar spectral signatures but the position of the first major $\mathrm{H}_{2} \mathrm{O}$ band centre at $1.44 \mu \mathrm{m}$ rather than $1.42 \mu \mathrm{m}$ together with the strong $2.22 \mu \mathrm{m}$ absorption identify these endmembers as gypsum rather than bassanite ${ }^{35}$. This is consistent with the Q-XRD results which found significant gypsum across the sample set but small amounts of bassanite in only two samples. In addition one endmember was unrealistic with negative values. Due to these issues, a variety of endmember combinations were fed into the FCLLS abundance estimation algorithm as a control. These included spectra taken from the USGS spectral library ${ }^{35}$ and the ASTER spectral library representing minerals known to be found in an environment such as the Atacama but not confidently identifiable as any of the endmembers extracted by SISAL. These USGS endmembers were scaled to the range of reflectance values represented in the sample dataset. The resulting abundance estimates for the calcium sulfate and chloride salts were compared to the XRD abundance values. The endmember set (Figure 3) comprising the SISAL endmembers extracted using $p=8$ identified as gypsum, Al-phyllosilicate, halite and shade (i.e. a low reflectance endmember taken to represent the shading of grains by other grains in the samples) as well as library spectra of albite, microcline, quartz, hematite, chlorite and calcite and an additional 'dark' endmember of a flat low reflectance spectrum returned the most accurate abundance estimates for calcium sulfates. When the three calcium sulfates in the samples were treated as one broad calcium sulfate endmember, all but one sample returned abundances within the error range of the XRD results (Figure 4). Anhydrite has a spectrally neutral signature in the NIR wavelength range and thus was not distinguishable in the unmixing. The halite abundance estimates were not within error using either the SISAL endmember or a USGS halite spectrum. It was concluded that halite has too weak of a spectral signature in this wavelength range to extract using an algorithm such as SISAL or to accurately estimate its abundance.

\footnotetext{
${ }^{*}$ SISAL Matlab code sourced from http://www.lx.it.pt/ bioucas/code.htm with kind permission of Bioucas-Dias. FCLLS Matlab code used in this study can be found within the HyperSpectralToolbox developed by David Kuhn and made available through github https://github.com/davidkun/HyperSpectralToolbox/blob/master/functions/hyperFcls.m
} 


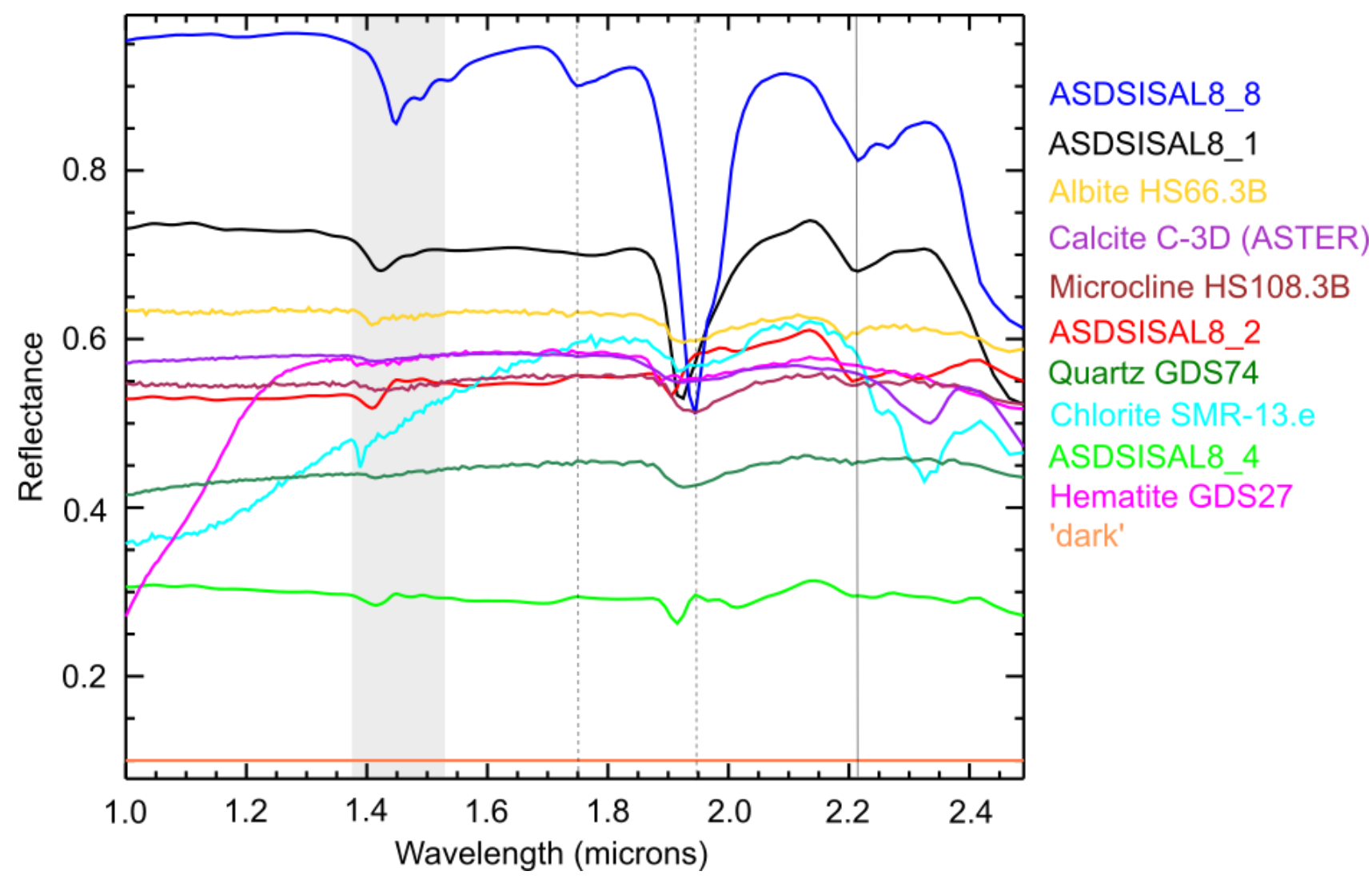

Figure 3: Laboratory final endmember spectra set comprising identifiable SISAL endmembers and scaled spectral library endmembers. Key absorptions identified in Figure 2 are also highlighted here. ASDSISAL8_8 is identified as gypsum, ASDSISAL8_1 is identified as an Al-phyllosilicate, ASDSISAL8_2 is tentatively identified as halite and ASDSISAL8_4 is included to represent the portions of returned spectra that come from portions of the sample shaded by other grains.
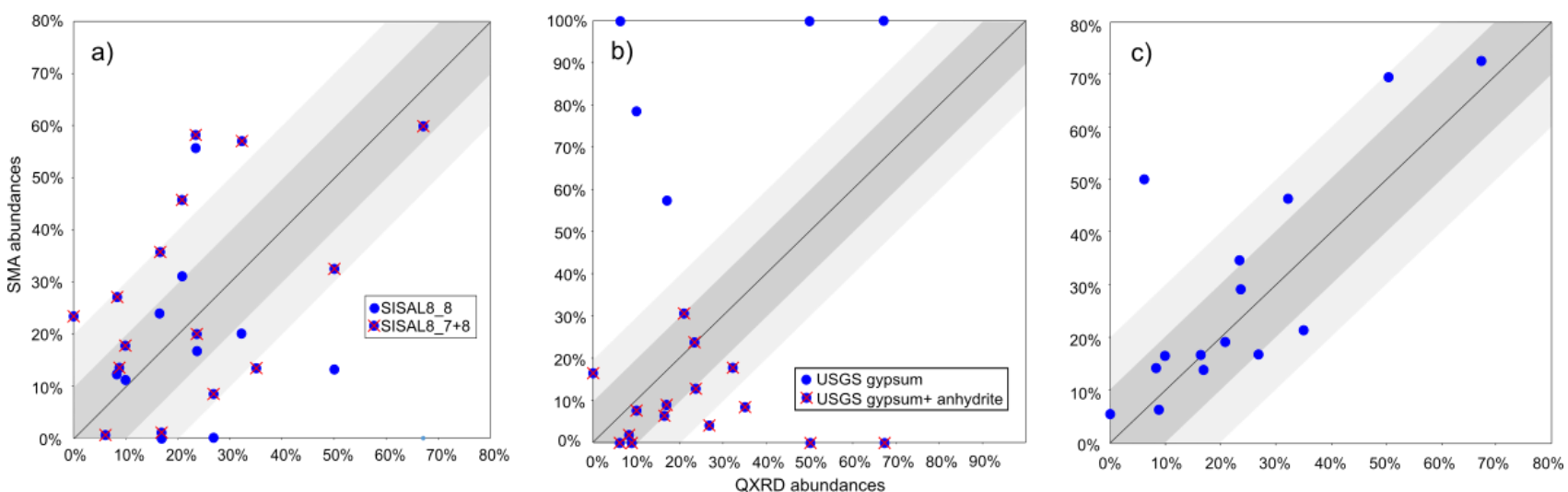

Figure 4: XRD calculated Ca-sulfate abundances vs SMA calculated Ca-sulfate abundances, a) abundances based on FCLLS using only SISAL extracted endmembers where the blue circles represent the abundances assuming only endmember 8 represents the Casulfates and the blue circles with red crosses showing the combined abundances from endmembers 8 and 7 both of which resembled gypsum but a high and low reflectance version respectively: b) abundances calculated from FCLLS using only scaled spectral library endmembers where blue circles represent abundances of gypsum and blue circles plus red crosses represent combined abundances of gypsum and anhydrite: c) Ca-sulfate abundances calculated using the endmember set comprising a mixture of SISAL and spectral library spectra. In all three plots the shaded regions represent $10 \%$ and $20 \%$ error respectively. As the XRD results are only correct to within $10 \%$ and as each sample had at least two different Ca-sulfate minerals in it the $20 \%$ error line represents an accurate match of the SMA abundances to the XRD abundances. 


\subsection{Hyperion NIR Images}

Eight Hyperion images were requested covering the four sample regions (Table 2). Each image was processed as described in section 2.3 and Regions of Interest (ROI) selected to cover the exact sample locations, incorporating as little topographic variation as possible to minimise photometric effects on the data. These ROIs were processed through SISAL using the same routine as outlined in Section 4.1 over $p=5-9$. When the resulting extracted endmembers were analysed only the September 2015 Yungay image returned an endmember set which was at least partially realistic with some endmembers identifiable as specific minerals. One endmember was identified as gypsum based on absorptions at 1.18, 1.53, 1.75 and $2.21 \mu \mathrm{m}$. Major diagnostic absorption features of gypsum at 1.45, 1.49 and $1.95 \mu \mathrm{m}$ are in regions that have been removed due to high probability of atmospheric water interference. Abundance estimation was performed first with the eight SISAL endmembers, then with a second set comprising a mixture of four SISAL endmembers (YungaySISAL8_2, 3, 4, 5) and scaled USGS spectra of calcite, albite, microcline, quartz and hematite, and thirdly with the second set augmented with an additional spectrally flat low reflectance 'dark' endmember (Figure 5). The XRD Ca-sulfate abundances across this area have a mean value of $13 \%$ spanning $0-23 \%$. The ASD unmixing abundances gave a mean value of $17 \%$ spanning a larger range of $6-35 \%$.

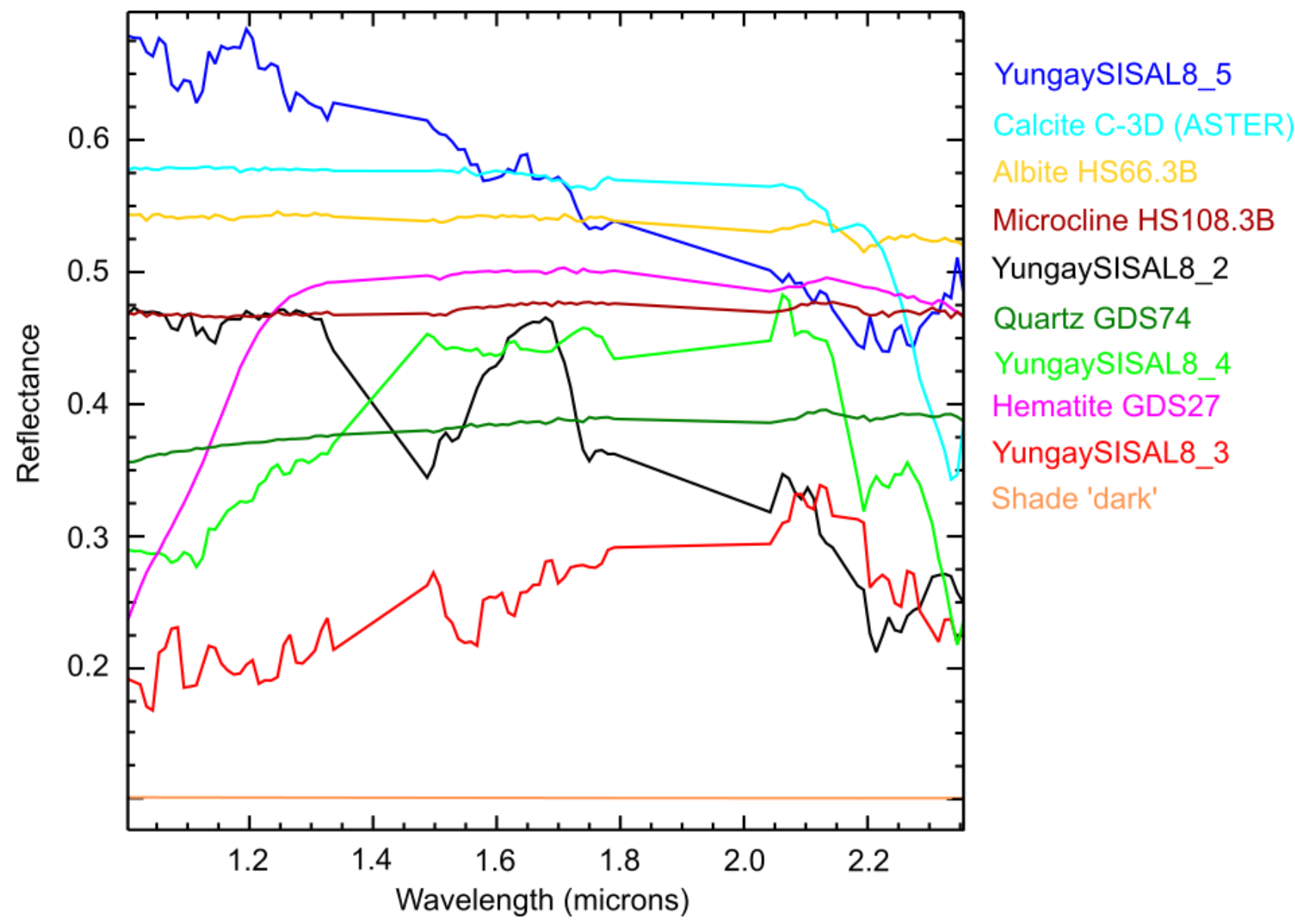

Figure 5: Final endmember set for Yungay September 2015 image comprising some SISAL extracted and some scaled spectral library endmembers. YungaySISAL8_2 is identified as gypsum.

The ROI was reconstructed using each endmember set and its corresponding estimated abundances and the RMSE calculated with respect to the original input image. This provided a check on the accuracy of the resulting abundances. The $p=8$ SISAL abundance set and the SISAL + USGS + 'dark' abundance set both returned an average Ca-sulfate abundance across the ROI of $10 \%$ with a peak value of $48 \%$. The SISAL + USGS set returned higher values with an average Ca- 
sulfate abundance of $24 \%$ with a peak value of $60 \%$. This latter set of abundances is erroneously high whilst the former largely agrees with the sample values. Additionally the average and peak RMSE values for the SISAL + USGS set were an order of magnitude larger than for the SISAL only set (average RMSE $=0.013$ compared to 0.0011), with the SISAL + USGS + 'dark' falling in the middle of these two (average RMSE $=0.005$ ). Using exact coordinates of the three samples from within this region that were analysed using Q-XRD, the corresponding pixel in each abundance image was examined. The pixel that corresponds to the location of sample Y2-AT12 (Figure 7) has a value of 28\% (SISAL + USGS), $14 \%$ (SISAL + USGS + 'dark') and 10\% (SISAL) compared to the XRD abundance of 23\%. Samples AT12-T1-19 and AT12T1-21 were taken within $1 \mathrm{~m}$ of each other and the pixel corresponding to their location (Figure 7) has values of $20 \%$ (SISAL + USGS), $11 \%$ (SISAL + USGS + 'dark') and 5\% (SISAL) compared to an average XRD abundance of $8 \%$. These two pixels both represent areas of the ground $29 \mathrm{~m}$ by $29 \mathrm{~m}$ in size and thus comparing them to samples of only $10 \mathrm{~s}$ of grams taken from one or two points within the region is not conclusive. Samples AT12-T1-19 and AT12-T1-21 were collected from either end of a $2 \mathrm{~m}$ transect and the compositional variation between these samples demonstrates how unrepresentative of a larger region a single sample can be. The endmember set SISAL + USGS + 'dark' did not return to lowest RMSE values across the ROI but it was still low with and average value of 0.005 and the average abundances agree with the sample average abundances. In addition the abundances calculated for both of the sample pixels are the consistently closest of the different endmember sets. Thus this endmember set is taken to be the most successful at estimating the abundance of calcium sulfate across this Hyperion image ROI.
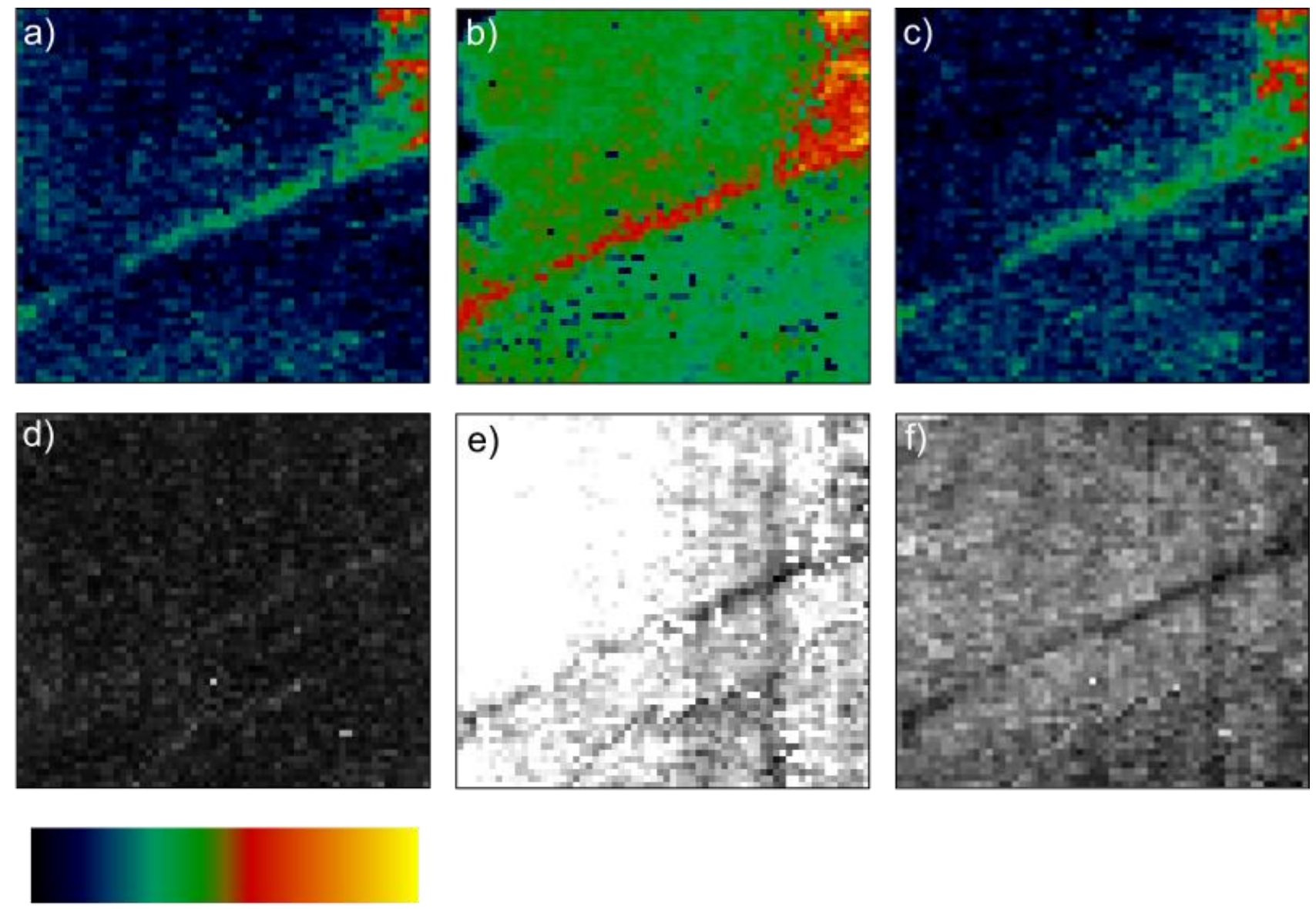

$0 \%$ $60 \%$

Figure 6: Yungay ROI Ca-sulfate abundance estimates from the SMA using and endmember set comprising a) SISAL extracted endmembers only, b) SISAL + spectral library endmembers where the Ca-sulfate endmember is YungaySISAL8_2 (Figure 5), c) SISAL + spectral library + 'dark' shade endmember. Yungay RMSE values from reconstruction of scene using SMA abundance results and endmember set comprising d) SISAL extracted endmembers only, e) SISAL + spectral library endmembers, f) SISAL + spectral library + 'dark' shade endmember. RMSE values range from 0 (black) to 0.01 (white). 


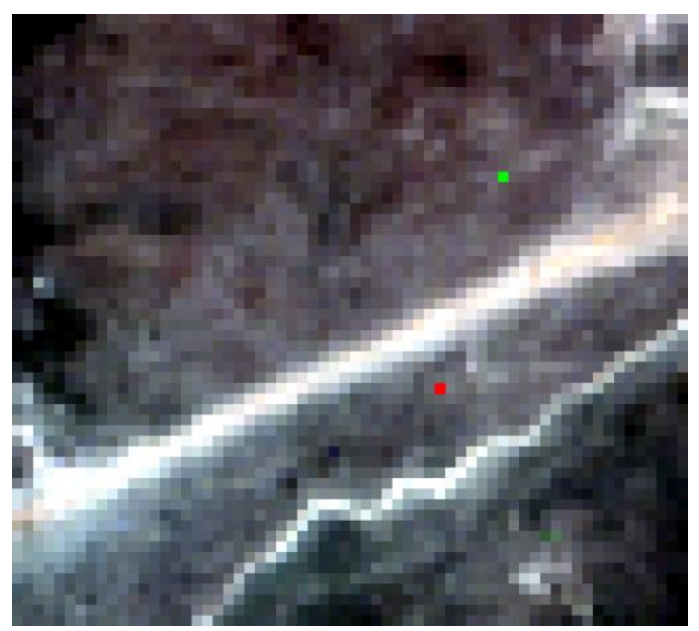

Figure 7: Location of samples Y2-AT12 (red pixel) and samples AT12-T1-19 and AT12-T1-21 (green) in the Yungay ROI shown in Figure 6.

\section{Discussion}

The results from the laboratory spectra showed that for salts with strong spectral features and sharp absorptions in the VNIR range, namely sulfates such as gypsum, SMA can identify them within a soil mixture. SMA can also provide an estimate of the volume abundance of sulfate minerals to within a 10-20\% margin of error, similar to that possible with QXRD analysis of these samples. The most accurate results however did rely on some prior knowledge of the minerals present to ensure a representative set of endmember spectra were used in the abundance estimation.

The Hyperion image analysis provided mixed results. Gypsum has strong features and was identifiable in the images and extractable by the SISAL algorithm. The resulting Ca-sulfate abundance estimates produced using an endmember set drawn from a mixture of SISAL extracted spectra and scaled USGS spectra were in agreement with the sample Q-XRD values from this area. Despite the extensive pre-processing outlined in this study only one of the eight final images had clean enough data to produce interpretable results with SMA. Hyperion returns the highest SNR data in the visible portion of its images but the diagnostic absorptions for those salts that have any in the VNIR are primarily above $1.5 \mu \mathrm{m}$ where the instrument SNR is poor. Together with the weak absorptions expected for many common chlorides and perchlorates, the high inherent noise and presence of strongly absorbing minerals meant that the only salt identifiable and quantifiable in the images was sulfate, in particular gypsum. Even in an area such as the Atacama Desert where there is a stable and predominantly cloud free atmosphere and the ground is well exposed, Hyperion struggles to provide data of sufficient quality for quantitative analysis. However, for exploration of planetary surfaces beyond Earth, such as Mars, it is likely that the techniques explored in this work would be potentially successful using hyperspectral data from the Compact Reconnaissance Imaging Spectrometer for Mars (CRISM) instrument on board the Mars Reconnaissance Orbiter. In particular, the successful identification and estimated quantification of sulfate minerals is highly applicable to Mars exploration, where sulfate minerals are abundant and record a significant part of Mars' surface history.

For both the laboratory and satellite spectral data the only identifiable salt is gypsum. The Q-XRD mineral analysis however revealed the presence of other calcium sulfates, primarily anhydrite. Anhydrite has a mostly neutral spectral signature which was not discernible in the spectral analysis. The abundance estimates from the SMA procedure are only a match to the XRD results when the endmember that resembles gypsum is taken to be representative of all the calcium sulfate minerals present. This is an important caveat to the results presented. Whilst the endmember used in the unmixing is identified as gypsum it is actually representative of calcium sulfate in the mixture, both the hydrous and anhydrous versions. Gypsum is the most commonly occurring form of calcium sulfate on the Earth, with anhydrite readily transforming into gypsum when exposed to water. Therefore for the purposes of quantifying this salt in surface soils the inability of the technique demonstrated in this study to distinguish between the two major forms of calcium sulfate is not considered a significant issue. 


\section{Conclusion}

In this study we have tested the ability of SMA to identify and quantify salt minerals in desert surfaces from VNIR spectral data using two well established algorithms SISAL and FCLLS. The Atacama Desert was chosen as a test site due to the high volume of multiple salt species in the surface soils and the regions high aridity. Laboratory spectra from surface and near-surface soil samples and Hyperion hyperspectral images covering the sample regions were both acquired providing two different spatial resolutions of data to test. The identification and abundance of the constituent minerals, including calcium sulfate and chloride salts, was confirmed using Q-XRD analysis providing a groundtruth to validate the SMA results. Analysis of the Hyperion images was hampered by the low SNR of the instrument in the key $2.0-2.5 \mu \mathrm{m}$ range resulting in a single image returning identifiable endmembers. The lack of strong spectral features in chlorides restricted the identification and quantification of these minerals in VNIR data, but SISAL was capable of extracting identifiable gypsum spectra from both the laboratory and Hyperion datasets. Using a combination of SISAL extracted spectra, including the gypsum endmember, together with some USGS spectral library spectra representing commonly found minerals in this type of environment, the abundance of calcium sulfate was accurately estimated using the gypsum endmember. Given a spectrally clean Hyperion image with high SNR, the techniques demonstrated here offer a computationally quick and simple method for remotely mapping the surface abundance of salt minerals with strong spectral features such as calcium sulfate with SMA.

\section{Acknowledgements}

This work was part-funded by a Research Incentive Grant from The Carnegie Trust (REF: 70335) and a Royal Society of Edinburgh Research Fellowship to C. Cousins. J, Harris acknowledges funding from STFC (consolidated grant ST/N000528/1). We would like to acknowledge support from Dr Alasdair MacArthur and the NERC Field Spectroscopy Facility and Dr Stuart Frye from NASA's Goddard Space Flight Centre.

\section{References}

[1] Drake, N. A., "Reflectance spectra of evaporite minerals (400-2500 nm): applications for remote sensing," Int. J. Remote Sens. 16(14), 2555-2571 (1995).

[2] Crowley, J. K., "Visible and near-infrared (0.4 - 2.5um) reflectance spectra of playa evaporite minerals," J. Geophys. Res. 96(B10), 16231-16240 (1991).

[3] Cloutis, E., Berg, B., Mann, P.., Applin, D., "Reflectance spectroscopy of low atomic weight and Na-rich minerals: Borates, hydroxides, nitrates, nitrites, and peroxides," Icarus 264, 20-36 (2016).

[4] Bishop, J. L., Ward, M. K., Roush, T. L., Davila, A. F., Brown, A. J., McKay, C. P., Quinn, R. C.., Pollard, W., "Spectral properties of $\mathrm{Na}, \mathrm{Ca}-, \mathrm{Mg}$ - and Fe-Chlorides and analyses of hydrohalite-bearing samples from Axel Heiberg Island," LPSC XXXXV, 2145, Houston, USA (2014).

[5] Mougenot, B., Pouget, M.., Epema, G. F., "Remote sensing of salt affected soils," Remote Sens. Rev. 7(3-4), 241-259 (1993).

[6] Crowley, J. K., "Mapping playa evaporite minerals with AVIRIS data: A first report from death valley, California," Remote Sens. Environ. 44(2-3), 337-356 (1993).

[7] Dehaan, R. L.., Taylor, G. R., "Mapping irrigation-induced salinity with hyperspectral imagery," IGARSS 2001. Scanning Present Resolv. Futur. Proceedings. IEEE 2001 Int. Geosci. Remote Sens. Symp. (Cat. No.01CH37217) 1, 293-295, IEEE (2001).

[8] Pieters, C. M.., Englert, P. A. J., Remote Geochemical Analysis: Elemental and Mineralogical Composition, 1st ed., C. M. Pieters and P. A. J. Englert, Eds., Cambridge University Press (1993).

[9] Barnsley, M. J., Settle, J. J., Cutter, M. A., Lobb, D. R.., Teston, F., "The PROBA/CHRIS mission: a low-cost smallsat for hyperspectral multiangle observations of the Earth surface and atmosphere," IEEE Trans. Geosci. Remote Sens. 42(7), 1512-1520 (2004).

[10] Pearlman, J., Carman, S., Segal, C., Jarecke, P., Clancy, P.., Browne, W., "Overview of the Hyperion Imaging Spectrometer for the NASA EO-1 mission,” IGARSS 2001. Scanning Present Resolv. Futur. Proceedings. IEEE 2001 Int. Geosci. Remote Sens. Symp. (Cat. No.01CH37217) 7, 3036-3038, IEEE, Sydney, NSW (2001).

[11] Magendran, T.., Sanjeevi, S., "Hyperion image analysis and linear spectral unmixing to evaluate the grades of iron ores in parts of Noamundi, Eastern India," Int. J. Appl. Earth Obs. Geoinf. 26, 413-426 (2014). 
[12] Hosseinjani Zadeh, M., Tangestani, M. H., Roldan, F. V.., Yusta, I., "Sub-pixel mineral mapping of a porphyry copper belt using EO-1 Hyperion data," Adv. Sp. Res. 53(3), 440-451 (2014).

[13] Ghosh, G., Kumar, S.., Saha, S. K., "Hyperspectral Satellite Data in Mapping Salt-Affected Soils Using Linear Spectral Unmixing Analysis," J. Indian Soc. Remote Sens. 40(1), 129-136 (2012).

[14] Valdivia-Silva, J. E., Navarro-González, R., Fletcher, L. E., Perez-Montaño, S., Condori-Apaza, R.., Mckay, C. P., "Soil carbon distribution and site characteristics in hyper-arid soils of the Atacama Desert: A site with Marslike soils," Adv. Sp. Res. 50(1), 108-122 (2012).

[15] McKay, C. P., Friedmann, E. I., Gómez-Silva, B., Cáceres-Villanueva, L., Andersen, D. T.., Landheim, R., "Temperature and Moisture Conditions for Life in the Extreme Arid Region of the Atacama Desert: Four Years of Observations Including the El Niño of 1997-1998," Astrobiology 3(2), 393-406 (2003).

[16] Azua-Bustos, A., Caro-Lara, L.., Vicuña, R., "Discovery and microbial content of the driest site of the hyperarid Atacama Desert, Chile," Environ. Microbiol. Rep. 7(3), 388-394 (2015).

[17] Ewing, S. A., Sutter, B., Owen, J., Nishiizumi, K., Sharp, W., Cliff, S. S., Perry, K., Dietrich, W., McKay, C. P., et al., "A threshold in soil formation at Earth's arid-hyperarid transition," Geochim. Cosmochim. Acta 70(21), 5293-5322 (2006).

[18] Ericksen, G. E., "Geology and origin of chilean nitrate deposits," U. S. Geol. Surv. Prof. Pap. 1188 (1981).

[19] Penrose, R. A. F., "The nitrate deposits of Chile," J. Geol. 18(1), 1-32 (1910).

[20] Sutter, B., Dalton, J. B., Ewing, S. A., Amundson, R.., McKay, C. P., "Terrestrial analogs for interpretation of infrared spectra from the Martian surface and subsurface: Sulfate, nitrate, carbonate, and phyllosilicate-bearing Atacama Desert soils,” J. Geophys. Res. Biogeosciences 112(G4), n/a - n/a (2007).

[21] Flahaut, J., Martinot, M., Potts, N. J.., Davies, G. R., "VNIR spectroscopy of the Atacama salars: An analogue study for Mars evaporate deposits," Eur. Planet. Sci. Congr., 84, EPSC, Nantes, France (2015).

[22] Cloutis, E. A., Hawthorne, F. C., Mertzman, S. A., Krenn, K., Craig, M. A., Marcino, D., Methot, M., Strong, J., Mustard, J. F., et al., "Detection and discrimination of sulfate minerals using reflectance spectroscopy," Icarus 184(1), 121-157 (2006).

[23] Folkman, M. A., Pearlman, J., Liao, L. B.., Jarecke, P. J., "EO-1/Hyperion hyperspectral imager design, development, characterization, and calibration," Proc. SPIE 4151, Hyperspectral Remote Sens. L. Atmos. 40, W. L. Smith and Y. Yasuoka, Eds., 40-51, SPIE, Sendai, Japan (2001).

[24] Datt, B., McVicar, T. R., Van Niel, T. G., Jupp, D. L. B.., Pearlman, J. S., "Preprocessing eo-1 hyperion hyperspectral data to support the application of agricultural indexes," IEEE Trans. Geosci. Remote Sens. 41(6), 1246-1259 (2003).

[25] Dadon, A., Ben-Dor, E.., Karnieli, A., "Use of Derivative Calculations and Minimum Noise Fraction Transform for Detecting and Correcting the Spectral Curvature Effect (Smile) in Hyperion Images," IEEE Trans. Geosci. Remote Sens. 48(6), 2603-2612 (2010).

[26] van der Meer, F. D., van der Werff, H. M. A., van Ruitenbeek, F. J. A., Hecker, C. A., Bakker, W. H., Noomen, M. F., van der Meijde, M., Carranza, E. J. M., Smeth, J. B. de., et al., "Multi- and hyperspectral geologic remote sensing: A review," Int. J. Appl. Earth Obs. Geoinf. 14(1), 112-128 (2012).

[27] Heylen, R., Parente, M.., Gader, P., “A Review of Nonlinear Hyperspectral Unmixing Methods," IEEE J. Sel. Top. Appl. Earth Obs. Remote Sens. 7(6), 1844-1868 (2014).

[28] Quintano, C., Fernández-Manso, A., Shimabukuro, Y. E.., Pereira, G., "Spectral unmixing," Int. J. Remote Sens. 33(17), 5307-5340 (2012).

[29] Bioucas-Dias, J. M. B., Plaza, A., Dobigeon, N., Parente, M., Du, Q., Gader, P.., Chanussot, J., "Hyperspectral Unmixing Overview: Geometrical, Statistical, and Sparse Regression-Based Approaches," IEEE J. Sel. Top. Appl. Earth Obs. Remote Sens. 5(2), 354-379 (2012).

[30] Bioucas-Dias, J. M. B., "A variable splitting augmented Lagrangian approach to linear spectral unmixing," 2009 First Work. Hyperspectral Image Signal Process. Evol. Remote Sens., 1-4, IEEE (2009).

[31] Heinz, D. C.., Chang, C.-I., "Fully constrained least squares linear spectral mixture analysis method for material quantification in hyperspectral imagery," IEEE Trans. Geosci. Remote Sens. 39(3), 529-545 (2001).

[32] Kruse, F. A., Lefkoff, A. B., Boardman, J. W., Heidebrecht, K. B., Shapiro, A. T., Barloon, P. J.., Goetz, A. F. H., "The Spectral Image Processing System (SIPS) - Interactive visualization and analysis of imaging spectrometer data," Remote Sens. Environ. 44, 145-163 (1993).

[33] Harris, J. K., "Visible and near infrared imaging spectroscopy and the exploration of small scale hydrothermally altered and hydrated environments on Earth and Mars," Birkbeck, University of London (2016).

[34] Jensen, H. B.., Glotch, T. D., "Investigation of the near-infrared spectral character of putative Martian chloride 
deposits," J. Geophys. Res. 116, E00J03 (2011).

[35] Clark, R. N., Swayze, G. A., Wise, R., Livo, E., Hoefen, T., Kokaly, R.., Sutley, S. J., "USGS digital spectral library splib06a: U.S. Geological Survey, Digital Data Series 231,” U.S. Geol. Surv. Digit. Data Ser. 231, 2007, <http://speclab.cr.usgs.gov/spectral.lib06.> (1 January 2012 ). 